\title{
RETROCESSO NA POLÍTICA NACIONAL SOBRE DROGAS: APROVAÇÃO DA RESOLUÇÃO DA ABSTINÊNCIA PELO CONSELHO NACIONAL DE POLÍTICAS SOBRE DROGAS
}

Naima Worm

Eric Jose Migani

\section{Resumo}

O artigo analisa o impacto da Resolução n. 01/2018 do Conselho Nacional de Políticas sobre Drogas - CONAD, que reorienta os programas, projetos e ações governamentais para a adoção da abstinência como fundamento para a construção de todo o programa nacional sobre drogas, em detrimento das ações de redução de danos, em aparente inconstitucionalidade do ato.

Palavras - Chave: Política pública nacional sobre drogas; abstinência; inconstitucionalidade da Resolução CONAD n. 01/2018; criminalização de usuários de drogas; redução de danos.

REGRESS IN THE NATIONAL DRUG POLICY: ADOPTION OF THE ABSTINENCE RESOLUTION BY THE NATIONAL DRUG POLICY COUNCIL

\section{Abstract}

The article analyzes the impact of Resolution n. 01/2018 of the National Council for Drug Policy - CONAD, which reorients government programs, projects and actions for the adoption of abstinence as the basis for building the entire national drug program, to the detriment of harm reduction actions, in apparent unconstitutionality of the act.

Key words: National public drug policy; abstention; unconstitutionality of Resolution CONAD n. 01/2018; criminalization of drug users; damage reduction.

Sumário: 1 Introdução. 2 Política nacional de drogas e os modelos existentes. 3 O retrocesso da política nacional sobre drogas com a adoção da Resolução CONAD n. 01/2018. 4 Elementos indicadores de violação à constitucionalidade da resolução CONAD n. 01/2018. Considerações Finais. Referências. 


\section{INTRODUÇÃO}

A instituição de uma política pública sobre drogas eficiente é um grande desafio aos governos, nas três esferas de poder, tendo em vista a complexidade das ações e o gigantismo do país. O modelo adotado até então, possui suporte na Lei n. 11.343/2006 e no Decreto 4345/2002. Esses documentos, apesar de possuírem um lastro do modelo de redução de danos, ainda criminalizam todo o contexto do uso de drogas, incluindo punições a usuários e dependentes.

Em abril de 2019 a Presidência da República editou o Decreto n. 9.761/2019 aprovando a política Nacional de Drogas. Na ocasião da edição do decreto ainda tramitava no Congresso Nacional projeto de Lei que propunha um realinhamento da política, culminando com a aprovação em junho da Lei 13.830/2019. O realinhamento proposta já vem dialogando com a política de endurecimento no enfrentamento às drogas discutida no âmbito do Conselho Nacional de Políticas sobre Drogas - CONAD que originou o presente artigo crítico.

Em 2018 o CONAD editou a resolução n. 01/2018 que previu uma postura radical pela não descriminalização das drogas e adoção da abstinência como regra geral a nortear todas as ações institucionais da política de drogas.

Dentro desse quadro de construção das políticas públicas sobre drogas, a criminalização aos usuários e dependentes sempre se mostrou como desafio a ser superado pela política nacional, tendo em vista que a sua descriminalização corresponde a um importante passo para que o Estado tenha controle sobre a circulação das substâncias entorpecentes, bem como projete ações de apoio aos usuários e dependentes com o objetivo de minar consideravelmente o mercado consumidor e desestimular o comércio de drogas.

Essa reforma na política de drogas era o esperado por parte de algumas das instituições que integram o Conselho Nacional de Políticas sobre Drogas - CONAD ${ }^{1}$,

\footnotetext{
${ }^{1}$ As entidades, grupos de pesquisa e outros coletivos, a exemplo da Associação Brasileira de Saúde Mental (ABRASME), o Laboratório de Estudos e Pesquisas em Saúde Mental e Atenção Psicossocial - FIOCRUZ, o Projeto Transversões (ESS-UFRJ), o Coletivo Pró-Frente em Defesa do SUS e da Reforma Psiquiátrica - RJ e o Grupo de Pesquisa em Políticas de Saúde e Saúde Mental (GPPS-UFSC), dentre outras instituições, criticaram a postura do presidente do CONAD, Ministro Osmar Terra, que cerceou o direito dessas entidades de se manifestarem quando da aprovação da resolução 01/2018, aprovada em 01/03/2018, com 16 votos dos 28 membros, que instaurou a abstinência e outros elementos retrógrados como regra da política nacional de drogas.
} 
com vistas a reforçar a redução de danos, sendo que para esses setores a descriminalização e o controle pelo Estado revelam um importante passo para o amadurecimento da política nacional.

Esse trabalho tem por escopo apresentar a Resolução CONAD n. 01/2018 que instituiu novas diretrizes para a política nacional sobre drogas e antecipou o posicionamento das normativas mencionadas (Lei 13.840/2019 e Decreto n. 9.761/2019), realizando os apontamentos necessários para subsidiar futuras discussões sobre o impacto desse novo direcionamento para a implementação de uma política eficaz, democrática e cidadã.

A problemática da pesquisa implica em apresentar possíveis ilegalidades e inconstitucionalidades da Resolução CONAD n. 01/2018 na política pública nacional sobre drogas e as consequências desse reordenamento da política para usuários e dependentes de substância entorpecentes a partir da adoção da abstinência como regra geral para o planejamento e execução dos programas e ações sobre drogas.

O Objetivo geral é apresentar as ilegalidades e inconstitucionalidades da Resolução CONAD n. 01/2018 na política pública nacional sobre drogas, que mudou a orientação estatal acerca do tema. Como objetivos específicos tem-se a apresentação dos três modelos de política sobre drogas; análise do conteúdo da Resolução CONAD n. 01/2018 demonstrando o retrocesso da política nacional sobre drogas; apresentar possíveis violações à constitucionalidade da resolução CONAD n. 01/2018.

A metodologia empregada utiliza o método descritivo analítico, alicerçado no estudo da legislação acerca das políticas públicas sobre drogas e a doutrina científica sobre o tema.

A primeira seção aborda os três modelos mais trabalhados pela doutrina para a formulação da política de drogas. A segunda seção analisa os impactos da Resolução CONAD n. 01/2018 na política nacional de drogas, sob a perspectiva do realinhamento da política para adoção do modelo proibicionista. A terceira seção apresenta possíveis ilegalidades e inconstitucionalidades da Resolução CONAD n. 01/2018.

\section{POLÍTICA NACIONAL SOBRE DROGAS E OS MODELOS MAIS UTILIZADOS NO ÂMBITO DOS GOVERNOS NACIONAIS}


A fim de esquematizar os modelos estatais de enfrentamento às drogas adotados em alguns países, serão trabalhados os três principais modelos, cada um com fundamentos e perspectivas de atuação diferentes: proibicionismo, abolicionismo e redução de danos.

O primeiro modelo está baseado na proibição absoluta ao consumo das drogas, acompanhado de medidas de força, aparato policial, penitenciário e sanções legislativas rígidas a consumidores e traficantes. Trabalha-se a política de drogas com o amparo de uma política criminal.

O segundo modelo, abolicionista, trata essencialmente da descriminalização das drogas e para tanto requer amadurecimento cultural e a presença de uma agenda política que fomente o investimento público e privado na política de drogas.

O terceiro modelo se adequa a uma postura mais moderada, baseado na desarticulação do mercado consumidor de drogas a partir de medidas que desestimulam o consumo e ofereçam apoio aos usuários e dependentes.

No modelo abolicionista e de redução de danos percebe-se o amparo das ações em uma política social forte, com vistas à promoção de uma melhor qualidade de vida da população em geral, tornando efetivos os seus direitos constitucionais por meio de políticas de emprego, de capacitação profissional, de saúde e outras ações de promoção e tutela da dignidade humana. Por sua vez, o modelo proibicionista se ancora em uma forte política criminal, as quais "atuam diretamente no fenômeno criminal, prevenindo os fatores etiológicos da criminalidade e reprimindo-a quando lesionados ou postos em perigo concreto os bens juridicamente protegidos" (RIBEIRO, 2013, p. 20).

O modelo proibicionista possui origem nos EUA e refletia a preocupação das oligarquias dominantes com a produtividade dos escravos e, posteriormente, da classe operária. A lógica da proibição está vinculada diretamente ao modo de produção capitalista, que exige dos trabalhadores uma potencialização laboral. Para isso, foram utilizados argumentos religiosos e leis restritivas para inibir o uso de drogas, marginalizando e criminalizando as pessoas que faziam o uso de álcool e outras drogas.

Atualmente, a política de proibição tem como foco o enrijecimento do aparelho de segurança pública, com o fortalecimento das polícias, do Poder Judiciário e do sistema penitenciário, com ênfase no controle de fronteiras, no enfrentamento ao tráfico e na abstinência forçada dos usuários de drogas. "Presume-se que a interdição pela lei penal, sob ameaça de pena, fará com que os indivíduos alterem seus costumes, gostos e escolhas, 
deixando de consumir determinadas substâncias pelo fato de serem ilícitas" (WEIGERT, 2010, p. 32).

A política proibicionista distinguiu "drogas legais e ilegais e [firmou] a convicção de que o único meio eficaz para lutar contra os danos produzidos pelas drogas ilegais é a repressão penal”. As proibições aos prazeres são uma restrição à autonomia do indivíduo, "efeito concreto do processo moralizador", implementado com maior ênfase no campo das drogas (WEIGERT, 2010, p. 31).

A utilização exclusiva de políticas proibicionistas revela um modelo fracassado, que mesmo tendo despendido um grande aporte de recursos econômicos não conseguiu reduzir no mercado a produção de produtos etiquetados como ilícitos e diminuir seu consumo (RIBEIRO, 2013).

Estudo recente da International Centre for Science in Drug Policy - ICSDP (2014), alerta que o sistema de "guerra às drogas" com ênfase em política criminal tem falhado, solidificando uma tendência internacional pela adoção da política de redução de danos em substituição à política proibicionista.

O segundo modelo abordado no trabalho refere-se à política abolicionista, com a proposta de descriminalização das drogas, de forma lenta e gradual, cuja aplicação deve ser em etapas, mesmo porque a criminalização já está arraigada nas instituições e na legislação construídas até aqui. A descriminalização legislativa, mecanismo de remoção da ilicitude penal, comporta três processos distintos:

(1) descriminalização legislativa em sentido estrito (abolitio criminis); (2) descriminalização parcial, substitutiva ou setorial, cujo processo é o de (2.1) transferência da infração penal para outro ramo do direito - v.g. direito administrativo sancionador - mantendo-se sua ilicitude jurídica, porém não penal e/ou de (2.2) alteração dos critérios sancionatórios, como a modificação nos critérios da tipicidade, flexibilização das penas ou de sua execução, criação de regras diferenciadas de extinção de punibilidade entre outros (reformatio legis in mellius) (CARVALHO, 2010, p. 109).

O abolicionismo possui como matriz o entendimento que as drogas sempre existiram, sejam elas legalizadas, como álcool, cigarros, remédios, chás etc, ou as criminalizadas pela legislação. O fato é que drogas existem e são consumidas clandestinamente, colocando em risco usuários e dependentes, com fomento ao tráfico e a violência, sendo que a guerra às drogas potencializa os riscos de violência social.

As sociedades conservadoras, com líderes políticos, religiosos, e econômicos que mantém um rígido controle sobre a população, tendem a adotar o modelo de proibição 
às drogas, criando situações-problemas, como a falsa informação de uma epidemia de crack, por exemplo, para penalizar e marginalizar usuários e dependentes de drogas e, assim, justificar o investimento de recursos financeiros e de pessoas na "luta" contra as drogas. Nesse contexto, cria-se uma imagem distorcida sobre o que é a descriminalização da drogas, estigmatiza usuários e dependentes e investem-se mais recursos em políticas criminais que os investimentos em políticas sociais.

Essa penalização tende a recair nos grupos mais vulneráveis, os quais citamos os negros, moradores de periferias, com baixo ou nenhum acesso aos serviços públicos, que já sofreram algum tipo de institucionalização, baixa escolaridade.

O terceiro modelo apresentado trata da redução de danos, enquanto medida de substituição ou minimização à criminalização no contexto de enfrentamento às drogas, alinhando política criminal, tratamento e prevenção. Esse modelo tomou maior corpo a partir da década de 90, com a distribuição de seringas e camisinhas aos usuários de drogas como enfrentamento à proliferação do vírus HIV, sustentada em pilares opostos às políticas proibicionistas (WEIGERT, 2010).

A redução de danos, na visão de pesquisadores, como Edson Passetti, possui um viés mais humano da drogadição, pois deixa de considerar usuários e dependentes como pessoas delinquentes e passa a enxergá-los como cidadãos,

O abolicionista trata cada caso como algo especial, como situaçãoproblema e não crime ou infração. Procura compreender a situação dos envolvidos, algozes e vítimas, tomando partido de ambos. (2005, p. 81).[...]

O dinheiro do Estado é meu, é seu, é de cada um. Se o gasto com prisões é imenso e ineficaz, porque não atuar de outra maneira? Não como alternativa punitiva à prisão. Para este caso já existe o regime das penas alternativas. Mas pela disseminação de práticas de redução de danos, respostas-percurso capazes de afirmar outras possibilidades de se conviver com drogas, sejam elas legais ou ilegais. (2005, p. 82).[...] Reduzir danos é uma política que reconhece essa milenar história do uso das drogas e atua segundo o interesse do usuário. É anti-repressiva, não idealiza a saúde, lida com o acontecimento no instante.

O modelo de redução de danos também se mostra como uma política de tolerância à própria história das drogas no mundo, que é utilizada desde a antiguidade em rituais espirituais sob o controle de autoridades religiosas (RIBEIRO, 2013). Ressalta-se que uso de substâncias psicoativas remonta a tempos imemoriais, em uma relação própria, a depender do momento histórico e cultural vivido na sociedade e, “[...] como uma narrativa mítica, esse uso é ressignificado em sintonia com as vicissitudes da história, ora 
com aspectos ritualísticos, ora com aspecto utilitário, criando, todavia, uma relação 'simbiótica', entre a substância e o sujeito que a utiliza” (ALBUQUERQUE, 2010, p. 13).

Em verdade, o modelo de redução de danos prevê a inserção do usuário em etapas de tratamento e apoio familiar, social e profissional com o objetivo de alcançar, paulatinamente, a redução do uso a níveis toleráveis e, até mesmo, a abstinência. Tratase da gestão do uso da droga, que possibilitará ao usuário e dependente fazer o uso racional de substâncias entorpecentes, garantindo melhor qualidade de vida.

A resolução CONAD n. 01/2018 está na via contrária à essas transformações, que priorizam o indivíduo e sua autonomia, ressuscitando com todas as forças o modelo proibicionista, revelando o caráter conservador e ideológico dos poderes constituídos, tornando temerário qualquer projeto de lei que pense uma reformulação da política nacional sobre drogas.

Vistos esses conceitos imprescindíveis para a compreensão dos três modelos de política sobre drogas, passaremos ao estudo da Resolução CONAD n. 01/2018 e suas possíveis violações à constituição e legislação em vigor na ocasião da sua edição.

\section{O RETROCESSO DA POLÍTICA NACIONAL SOBRE DROGAS COM A ADOÇÃO DA RESOLUÇÃO CONAD N. 01 DE 2018}

A política Nacional sobre drogas estava ancorada na Lei n. 11.343/2006 e no Decreto 4345/2002, que instituíam, na ocasião da edição da Resolução CONAD n. 01/2018, as regras gerais, as diretrizes comuns da política nacional e regras específicas para as ações da União.

Em 01 de março de 2018 o CONAD aprovou a Resolução n. 01/2018 com a proposta de fortalecimento da política nacional sobre drogas, aprovada sob os protestos de alguns segmentos que integram o CONAD, o qual passaremos a tratar.

$\mathrm{O}$ atigo $1^{\circ}$, II traz na sua redação que as novas diretrizes vem de encontro com o desejo da população brasileira,

II - A orientação central da Política Nacional sobre Drogas deve considerar aspectos legais, culturais e científicos, em especial a posição majoritariamente contrária da população brasileira quanto às iniciativas de legalização de drogas; (g.n.).

Com relação a esse ponto, não há registro de nenhum tipo de consulta ou mobilização da sociedade civil. Não foi realizado plebiscito ou audiências públicas, que 
envolvessem as instituições e entidades interessadas na discussão do tema, sendo que algumas opções feitas na resolução, a exemplo da abstinência, são questionáveis pela comunidade científica.

Para que se conclua que um posicionamento é majoritariamente a vontade de uma nação minimamente essa nação deve ser consultada de alguma forma. A afirmação, apesar de ser o posicionamento oficial do Conselho, expresso em resolução, é temerária, pois lhe falta subsídios técnicos para tanto, recaindo em posicionamentos pessoais e ideológicos do grupo com maioria no Conselho.

Ademais, não houve consenso na aprovação da resolução, sendo que o áudio da reunião, ocorrida em 01 de março de 2018, disponibilizado pelo Ministério da Justiça, reflete preocupação com relação à legitimidade do conteúdo da resolução ${ }^{2}$.

O Ministério da Justiça disponibilizou o áudio completo e a ata da reunião de aprovação da resolução CONAD n. 01/2018 ${ }^{3}$, sendo que alguns Conselheiros argumentaram em favor da manutenção da política de redução de danos ${ }^{4}$. Um ponto que aparentemente se apresentou como temerário à democracia nas votações do Conselho refere-se ao cerceamento de fala e negativa de vistas do processo à representante do Conselho Federal de Psicologia, sob o argumento que na reunião anterior já havia sido dado vista coletiva aos membros do conselho, ora contestada pela solicitante ${ }^{5}$. A legitimidade da reunião que aprovou a Resolução é temerária, sob o ponto de vista da

\footnotetext{
${ }^{2}$ A FIOCRUZ divulgou no seu site oficial informações questionando a legitimidade com que aconteceu o encontro que aprovou a resolução CONAD n. 01/2019: "Para a representante no Conad do Conselho Federal de Psicologia (CFP), Clarissa Guedes, a votação foi uma vitória pessoal de Osmar Terra. Embora o ministro tenha tomado posse em agosto de 2016 para a cadeira que cabe ao ministério do Desenvolvimento Social, numa autonomeação, Terra nunca havia comparecido as reuniões. A reunião que antecedeu a aprovação da proposta do ministro foi feita no apagar das luzes de 2018, poucos dias antes do Natal. Havia pelo menos um ano que o conselho não se reunia.

"A ideia deles era aprovar ali, mas pedimos o cumprimento do regimento, com discussões prévias sobre o assunto e o funcionamento de um grupo de trabalho, o que é básico, e que nos foi negado, então foi feito um pedido de vista. Marcaram a reunião já para o começo do ano, e acredito que porque o ministro irá se descompatibilizar do cargo em breve para disputar as eleições. Aquele momento foi feito para responder as bases políticas do ministro", afirma a conselheira.

Ao contrário das reuniões usuais do conselho, feita em uma sala comum dentro do Ministério da Justiça, a reunião da aprovação ocorreu em um grande salão de convenções com a participação da imprensa, onde Terra fez um longo discurso em defesa das internações involuntárias e contra a descriminalização das drogas. (FIOCRUZ, 2019).

${ }^{3} \mathrm{O}$ áudio da reunião com 1 hora e 27 min foi disponibilizado no site do Ministério da Justiça.

${ }^{4}$ Falaram em favor da redução de danos: Fabíola Xavier Leal

${ }^{5}$ No áudio manifestaram pedido de vistas os conselheiros: Vinicyus Ferreira dos Santos, Francisco Inácio Pinkusfeld Monteiro e Solange Moreira. (MINISTÉRIO DA JUSTIÇA. Áudio reunião CONAD, 2019).
} 
horizontalidade dos membros integrantes. (MINISTÉRIO DA JUSTIÇA CONAD. Conselho Nacional de Políticas sobre Drogas. Áudio reunião CONAD, 2019).

A resolução apresenta dispositivos polêmicos, os quais foram contestados na própria reunião de aprovação da resolução e em outros espaços de discussão. $\mathrm{O}$ artigo $1^{\circ}$, IV, consta

IV - O fomento e incentivo aos programas de prevenção próprios ou adaptados à realidade brasileira em articulação com organismos internacionais devem ser direcionados exclusivamente às iniciativas cujos resultados de impacto sejam satisfatoriamente mensuráveis no cumprimento dos objetivos de proteção; (grifo nosso).

Com relação à esse dispositivo, o Conselheiro Francisco Inácio Punksfeld Bastos, representante da Sociedade Brasileira para o progresso da Ciência, solicitou a alteração do termo exclusivamente para prioritariamente, uma vez que "o artigo $1^{\circ}$ inciso $4^{\circ}$ (sic), parece não compatível com as consultas feitas na OMS e os estatutos da UNODOC", destacando que "os dados compilados pelo MJ são perigosos e expõe a sociedade a risco". Ainda, sugeriu a substituição da palavra satisfatoriamente mensurável, pela expressão "que sejam baseados em dados empíricos consistentes” e o acréscimo, ao final, da expressão “proteção e alerta de eventuais riscos”. (MINISTÉRIO DA JUSTIÇA, CONAD. - Conselho Nacional de Políticas sobre Drogas. Ata n. 2 da reunião ordinária, 2018).

O referido destaque foi rejeitado pelos membros do Conselho, mantendo a redação original da proposta apresentada pelo Ministro Osmar Terra, representante do Ministério do Desenvolvimento Social e Agrário do Brasil ${ }^{6}$.

A Sociedade Brasileira para o progresso da Ciência lançou nota acerca da aprovação da Resolução,

Bastos alerta ainda que as sugestões expostas na resolução aprovada na última semana são, em sua maioria, genéricas e apontam apenas para uma consonância daquilo que é proposto com um projeto de lei de 2013, em discussão no Senado, de autoria do então deputado federal Osmar Terra. "Se o projeto não está aprovado não tem validade. Mas eles pensam diferente, tanto que se esforçaram ao máximo para aprovar. Acho que não haveria tanto esforço para algo inócuo",diz.[...]

$\mathrm{Na}$ avaliação de Ribeiro, o governo conseguiu uma vitória expressiva no Conad, "trocando representantes, substituindo pessoas, marcando reuniões a toque de caixa, dificultando ao máximo a representação da

\footnotetext{
${ }^{6} \mathrm{Na}$ ocasião da reunião a presidência era exercida pelo Ministro de Estado da Justiça Torquato Jardim e amplamente defendida pelo Ministro do Desenvolvimento Social e Agrário do Brasil Osmar Gasparini Terra.
} 
sociedade civil". (SBPC - Sociedade Brasileira para o progresso da Ciência, 2018).

Prosseguindo, o artigo $1^{\circ}$, inciso VI trata da necessidade de "imediata integração institucional e legal da gestão de programas entre os Ministérios da Saúde, Desenvolvimento Social, Trabalho, Justiça, Extraordinário da Segurança Pública e Direitos Humanos", todavia, não explicita como ocorrerão os arranjos institucionais que possibilitarão essa integração.

Todos os órgãos mencionados estão situados no primeiro escalão governamental, com agendas políticas próprias, cujos titulares não estão vinculados juridicamente à resolução do CONAD. A resolução é silente quanto à indicação de qual órgão funcionará como integrador dos demais, a função que cada um ficará responsável, a nominação dos cargos responsáveis por essa integração, ou seja, detalhamentos indispensáveis à efetividade da normativa.

Ainda, o artigo $1^{\circ}$, o $\S 2^{\circ}$ trata do fomento contínuo que deverá ser ofertado às entidades da organização da sociedade civil, com ênfase na comunidades terapêuticas.

$\S 2^{\circ}$ - A União deve promover de forma contínua o fomento à rede de suporte social, composta por organizações da sociedade civil e de prevenção, acolhimento, inclusive em comunidades terapêuticas, acompanhamento, mútua ajuda, apoio e reinserção social, definindo parâmetros e protocolos técnicos com critérios objetivos para orientação das parcerias com a União.

O Ministério da Justiça, por meio da SENAD - Secretaria Nacional de Políticas sobre Drogas, divulgou a relação de Comunidades Terapêuticas com contratos em vigência com o governo federal, totalizando quase cem milhões de reais investidos em $2019^{7}$.

As comunidades terapêuticas, apesar de integrarem a Rede de Atendimento Psicossocial - RAPS, constituem-se em espaços privados e com pouca, ou nenhuma, fiscalização, podendo ainda, em longo prazo, refletir na diminuição da prestação de outros serviços de acolhimento, como os Centros de atenção psicossociais - CAPS.

A situação de flagrante violação aos direitos e garantias fundamentais foi documentada no relatório elaborado pelo Conselho Federal de Psicologia, juntamente com o Ministério Público em 2017, que apontou situações de cárcere, maus tratos e outras situações de flagrante desrespeito aos direitos humanos. (Conselho Federal de Psicologia;

\footnotetext{
${ }^{7}$ A SENAD divulgou o gasto de $R \$ 99.635 .619,84$ com 326 comunidades terapêuticas com contratos vigentes junto à União.
} 
Mecanismo Nacional de Prevenção e Combate à Tortura; Procuradoria Federal dos Direitos do Cidadão / Ministério Público Federal, 2018).

O relatório, que merece ser lido por todos que estudam a temática, traz um panorama atualizado (2017) do que foi encontrado nas visitas feitas às 28 comunidades terapêuticas distribuídas em 12 unidades da federação, com descrição detalhada do caráter asilar, as internações involuntárias e compulsórias, os aspectos institucionais, as equipes de trabalho, o uso da força, dentre outros pontos fiscalizados.

São muitos os aspectos das comunidades terapêuticas examinados pela comissão que as fiscalizaram, fazendo clara indicação que são pessoas/pacientes em situação de segregação e isolamento, em condição de desconformidade os parâmetros normativos tutelam a saúde mental no Brasil, em flagrante violação, como dito, aos direito humanos, os quais citamos o direito de ir, vir e permanecer, sigilo de correspondências, incomunicabilidade dentre outros.

A crítica aos procedimentos adotados nas Comunidade Terapêuticas são extensas, uma vez que adotam o isolamento, trabalhos forçados e prática religiosa obrigatória como fundamentos do tratamento, em detrimento às recomendações da política nacional de saúde mental, que preconiza a manutenção dos laços familiares, apoio médico e psicológico e tratamentos que não privem as pessoas do convívio social.

A inclusão das comunidades terapêuticas na rede de atendimento, bem como o foco que está sendo dado pela Resolução CONAD n. 01/2018 preocupa as instituição que cuidam da saúde mental e possuem assento no CONAD pela proximidade com as antigas práticas manicomiais abolidas pela política de saúde mental no país. Está sendo ressuscitado um gigante adormecido que foi responsável por um número imensurável de violações aos direitos humanos, que se estenderam por décadas no Brasil, a exemplo do Hospital Psiquiátrico de Babarcena $-\mathrm{MG}^{8}$.

$\mathrm{O}$ artigo $2^{\circ}$ trata dos desdobramentos da resolução, em afronta à distribuição de competência legislativa do texto constitucional, pois já no inciso I prevê a reorganização dos "documentos legais" a partir do texto da resolução. O processo é inverso, a lei dirige os atos legislativos e administrativos complementares.

\footnotetext{
${ }^{8}$ O hospital psiquiátrico de Barbacena, fundado em 1903, em Barbacena-MG, tornou-se conhecido pelo tratamento desumano que oferecia aos seus paciente. Para o Colônia, eram enviados "pessoas não agradáveis", como opositores políticos, prostitutas, homossexuais, mendigos, pessoas sem documentos, entre outros grupos marginalizados na sociedade.
} 
O inciso II refere-se ao dever de atualização do governo brasileiro com relação aos Organismos Internacionais seguindo as orientações da resolução. O inciso III dispõe “A adequação de ações, projetos e programas, observando o disposto na presente Resolução". Ambos também padecem do vício de inconstitucionalidade formal e material, uma vez que violam a distribuição competência legislativa estabelecida no texto constitucional e usurpam o conteúdo que deveria ser tratado em lei, não ato administrativo.

O Governo Federal já está aplicando a resolução, tanto que já determinou a substituição da expressão redução de danos, por abstinência nos projetos e ações governamentais. Exemplo desse realinhamento ocorreu com o projeto desenvolvido pelo Centro Regional de Referência de Drogas da Universidade Federal do Tocantins, o qual integramos a equipe, que teve a expressão "redução de danos" substituída por "abstinência", modificando toda estrutura no qual se pautava as ações do CRR. ${ }^{9}$

Vistos esses elementos do conteúdo da resolução que tratam do realinhamento da política sobre drogas, passar-se-á à análise dos aspectos jurídicos da resolução, apresentando violações à legalidade e constitucionalidade do ato normativo.

\section{ELEMENTOS INDICADORES DE VIOLAÇÃO À CONSTITUCIONALIDADE DA RESOLUÇÃO N. 01/2018}

Os atos administrativos são, por excelência, a forma de manifestação de vontade do Estado, devendo observar os requisitos inerentes à sua validade, estabelecidos pelo Direito Público com o objetivo de criar, modificar ou extinguir direitos, sempre perseguindo o atendimento do interesse público.

Dentro do ideal de repartição de funções públicas, compete ao Poder Judiciário julgar. Nesse propósito, exerce o poder de controle judicial e, quando necessário, revisão dos atos administrativos emitidos pelos demais poderes e pelo próprio Poder Judiciário. Trata-se do exercício de uma função típica, celebrada na repartição de poderes montesquiana, atingindo todos os elementos do ato administrativo, inclusive a

${ }^{9}$ O CRR SUL - UFT atua nas ações extensionistas do programa de capacitação de agentes da política de drogas, e teve todo material de trabalho do projeto reformulado para atender as novas diretrizes da Resolução n. 01/2018, substituindo redução de danos por abstinência. 
discricionariedade, com a observância dos princípios constitucionais - explícitos e implícitos - e respeito aos direitos humanos.

O controle judicial é exercido privativamente pelos órgãos integrantes do Poder Judiciário sobre os atos administrativos do Executivo, Legislativo e Judiciário, verificando, posterior à sua edição, se foram emanados conforme as regras que os regem.

As resoluções dos Conselhos possuem natureza jurídica de ato administrativo, dentro da categoria dos atos administrativos normativos, sujeitando-se também ao controle de legalidade e constitucionalidade, devendo respeitar a hierarquização do sistema normativo brasileiro.

As resoluções de conselhos dotados de densidade normativa podem ser objeto de Ação Direta de Inconstitucionalidade - ADI, a exemplo de outras resoluções de conselhos que já foram objeto de ADI propostas no STF, sendo que a presente resolução, aparentemente, padece de flagrante vício de inconstitucionalidade orgânica também chamada de violação a pressupostos do ato, em razão da elaboração por autoridade incompetente, bem como vício material, por ferir, com a proposta de abstinência, o direito à saúde e à dignidade da pessoa humana.

Para explicitar a natureza desse vício, citamos o exemplo dos municípios quando legislam sobre matérias de competência da União, usurpando a competência previamente estabelecida no texto constitucional.

No caso em tela, o Conselho legislou sobre matéria que não lhe cabia, mas sim ao Poder Legislativo federal, por meio de lei, gerando o vício de inconstitucionalidade formal. Quanto ao conteúdo, violou a Constituição Federal, no direito à saúde e à dignidade da pessoa humana, ao prever a abstinência como modelo a ser adotado pela política.

A resolução versa de conteúdo que deveria ser tratado na lei, e não por meio de ato normativo do conselho, inclusive porque inova no mundo jurídico exercendo a função típica do Poder Legislativo.

Analisando o ato administrativo editado, verifica-se uma usurpação de competência, pois o CONAD excedeu os limites de sua competência regulamentar, ferindo a norma hierarquicamente superior quanto à forma. O ordenamento jurídico brasileiro é regido pelo escalonamento de normas, nas quais as inferiores devem obedecer as superiores. 
O poder de expedir Resoluções, conferido pelo ordenamento jurídico ao CONAD, lhe confere poderes para disciplinar algumas matérias no âmbito do Sistema Nacional de Políticas Públicas sobre Drogas - SISNAD. Porém, ao expedir a Resolução ele avançou nas funções, criando uma lei propriamente dita.

O Decreto $n^{\text {o }} 5.912 / 2007$ que regulamentou a Lei $n^{\text {o }} 11.343 / 2006$ confere ao CONAD competência para expedir Resoluções (artigo $4^{\circ}$ ), devendo manter-se adstrito às matérias ali especificadas:

\footnotetext{
Art. $4^{\circ}$ Compete ao CONAD, na qualidade de órgão superior do SISNAD:

I - acompanhar e atualizar a política nacional sobre drogas, consolidada pela SENAD;

II - exercer orientação normativa sobre as atividades previstas no art. $1^{\mathrm{o}}$;

III - acompanhar e avaliar a gestão dos recursos do Fundo Nacional Antidrogas - FUNAD e o desempenho dos planos e programas da política nacional sobre drogas;

IV - propor alterações em seu Regimento Interno; e

V - promover a integração ao SISNAD dos órgãos e entidades congêneres dos Estados, dos Municípios e do Distrito Federal. (BRASIL, Decreto $n^{\circ}$ 5.912/2007).
}

A regra que dispõe sobre a repartição de competência ente os entes federados e poderes constituídos é de restrição, limitando o exercício normativo que cada qual pode exercer. Visa o texto constitucional conferir autonomia e harmonia entre os entes, a fim que o pacto federativo não seja rompido.

Possíveis violações às regras para legislar devem ser solucionadas pelo Poder Judiciário, que no cenário republicano possui a competência para dizer o direito.

A prática de todo e qualquer ato administrativo exige o cumprimento de alguns preceitos do Direito Administrativo para que não incorra em ato viciado. São eles o sujeito, o objeto, a forma, o motivo e a finalidade. A ausência da observância a esses requisitos expõe o ato à anulação, que poderá ser feita pela própria administração pública ou pelo Poder Judiciário.

Sistematizando os vícios aparentes da Resolução, é possível identificar vício quanto ao sujeito, pois a norma construída é de natureza legislativa, inovando no mundo jurídico, com matéria de competência da lei, e não de ato regulamentar.

Ainda, há na resolução o vício quanto à motivação do ato, ou seja, vício na indicação da justificação do ato administrativo. Os considerandos da resolução são 
frágeis e não justificam a adoção da abstinência como modelo a ser seguido, sendo que o artigo $1^{\circ}$, II alude a "uma posição majoritária da população brasileira contra a legalização e descriminalização de drogas", sem que essa afirmação seja comprovada.

Já na reunião de aprovação da resolução as motivações apresentadas pelo Ministro do Desenvolvimento Social e Agrário do Brasil Osmar Terra, não se relacionam com as apresentadas no texto do documento, possuindo um viés manifestamente ideológico, contrário ao que se produziu até o presente momento com a política de redução de danos.

Os motivos apresentados no discurso de defesa da proposta da resolução são incompatíveis aos motivos intrínsecos da lei que institui a política nacional sobre drogas. (Ministério da Justiça, Áudio da reunião, 2018)

Por fim, identificou-se vício quanto à finalidade do ato administrativo, pois o objetivo apresentado na resolução é o reordenamento da política nacional sobre drogas (usurpando matéria privativa de lei), sendo que na verdade o que a resolução fez foi instituir como regra geral a adoção da abstinência, contrariamente à lei, que adota o modelo de a redução de danos.

Avançando na análise da inconstitucionalidade, percebe-se a presença de vícios materiais, em flagrante violação à Constituição Federal e justificadores da anulação do ato pelo Poder Judiciário. Dois importantes direitos estabelecidos no texto constitucional são corrompidos com a resolução, o direito à saúde e o direito à dignidade da pessoa humana.

A proteção no artigo 196 da Constituição Federal refere-se tanto à saúde sob o aspecto universal, em que todos têm direito de acesso à rede, como impõe o dever ao Estado em oferecê-la, dentro dos parâmetros desenvolvidos na legislação complementar.

Trata-se de uma política empregada pelo Estado para manutenção de uma sociedade saudável, com medidas preventivas e de redução de danos, consideradas de relevância pública.

A exigência da abstinência como única opção na construção das políticas públicas corrompe toda construção histórica de oferta de serviços de saúde com vistas à redução de danos, já implementada pela rede SUS. Atualmente compõem a rede de atendimento do SUS, para a política nacional de saúde mental, álcool e outras drogas: Serviço Residencial Terapêutico (SRT); Unidade de Acolhimento (adulto e infantojuvenil); Enfermarias Especializadas em Hospital Geral; Hospital Psiquiátrico; Hospital- 
Dia; Atenção Básica; Urgência e Emergência; Comunidades Terapêuticas; Ambulatório Multiprofissional de Saúde Mental. (Ministério da Saúde, 2019).

A adoção da abstinência vem de encontro com a inclusão das comunidades terapêuticas nesse rol de aparelhos do SUS para a política sobre drogas, uma vez que a abstinência constitui-se como único mpetodo de trabalho das comunidades. Este trabalho não tem por objetivo analisar as violações a direitos promovidos pelas comunidades terapêuticas, principalmente após a publicação do relatório de inspeção feito pelo Conselho Federal de Psicologia e o Ministério Público Federal que merece uma pesquisa própria, mas cita a falência desse modelo manicomial para demonstrar a violação aos direitos à saúde e dignidade da pessoa humana.

A Resolução n. 01/2018 apresenta violações ao texto constitucional no que se refere à negligência com que trata as pessoas dependentes de álcool e drogas, uma vez que exigir delas a abstinência como única e exclusiva forma de tratamento é ignorar a complexidade do assunto e toda a metodologia já desenvolvida pela ciência da saúde.

Sarlet, Marinoni e Mitidiero (2013) abordam o direito à saúde com uma íntima vinculação aos direitos à vida e dignidade da pessoa humana, tratando do direito à vida como uma deflagração dos demais direitos, pré-condição para a própria dignidade da pessoa humana, interligando-o aos direitos à alimentação, ambiente saudável, moradia dentre outros.

Para Maria Celina Bodin de Moraes (2017), o princípio da dignidade da pessoa humana é "o valor supremo de alicerce da ordem jurídica democrática", constituindo-se em um direito que fundamenta toda a construção democrática constitucional. Verdadeiro alicerce da república.

A dignidade da pessoa humana corresponde a fundamento republicano devendo ser considerada em qualquer ato, tanto público como privado.

A desconsideração que as drogas sempre existiram e continuarão a existir, bem como que o álcool além de ser uma droga legalizada é socialmente valorizado, são elementos que a política de abstinência não leva em consideração, realizando um único corte: o uso ou não de drogas e álcool. Não haverá adoção de etapas para o atingimento da abstinência. Entrou-se na regra do tudo ou nada, o que para a política sobre drogas representa uma ameaça à dignidade de usuários e dependentes.

A questão referente à constitucionalidade da Resolução n. 01/2018 ainda não foi levada à análise do Poder Judiciário, sendo que seus dispositivos estão repercutindo 
efeitos como se fosses constitucionais, comprometendo a validade e eficácia das regras que dispõe sobre a política de drogas no país.

Por fim, o texto buscou criar alguns subsídios jurídicos que contribuam para a reflexão da política nacional sobre drogas e a necessidade de proteção do modelo de redução de danos frente aos ataques ideológicos e de endurecimento criminal.

\section{CONSIDERAÇÕES FINAIS}

A pesquisa teve por objetivo apresentar e discutir as regras trazidas pela aprovação da Resolução CONAD n. 01/2018 que propôs o realinhamento da política nacional sobre drogas, alterando o modelo de redução de danos para incorporar a abstinência total de usuários e dependentes aos programas, projetos e ações em curso, bem como aos que serão implementados.

A política de drogas é uma das mais complexas e desafiadoras, para governo e sociedade, uma vez que envolve questões culturais, econômicas, de saúde, educação, assistência social e segurança pública. São muitos os setores chamados a integrar essa política, que possui sua natureza baseada na intersetorialidade.

O estudo da história do uso de entorpecentes demonstra a existência imemorial do seu consumo entre os povos, seja na antiguidade para fins religiosos ou festas pagãs, seja como instrumento de contestação política, ou para fins de recreação ou associado a algum transtorno mental, como se vê na atualidade. São muitos os usos, sendo que o Brasil possui drogas potencialmente nocivas legalizadas, como álcool e remédios, e drogas proibidas, cujo rol é fixado por portaria da ANVISA.

São várias as razões para adoção do modelo de redução de danos em detrimento ao modelo de abstinência, desde o fortalecimento de políticas sociais que fomente o elemento cidadania, enxergando usuários e dependentes como sujeitos de direitos, e não objeto de ações governamentais, até a adoção de políticas de saúde que conservem os laços familiares e sociais em detrimento ao modelo de internação.

Quanto ao aspecto criminal, a redução de danos fortalece a adoção de políticas sociais em diminuição às políticas criminais. O cuidado aos usuários e dependentes gradativamente reduz o mercado consumidor das drogas, melhora as condições de vida das populações marginalizadas, empoderando as comunidades para que integrem essas ações de maneira protagonista. 
Ao expedir a Resolução n. 01/2018 o CONAD extrapolou suas funções, tratando de matéria que é de competência da lei e somente o Poder Legislativo poderia legislar, apresentando um vício formal de constitucionalidade, bem como violou o conteúdo da legislação preexistente e hierarquicamente superior, ao determinar a abstinência como regra para a política de drogas, sendo que a lei não a prevê e contraria a melhor interpretação acerca dos princípios da dignidade da pessoa humana e saúde.

Ainda, determinou que a legislação existente seja reordenada a partir da Resolução, bem como o posicionamento do Brasil perante os organismos internacionais, contrariando o sistema de hierarquia normativa, que disciplina a ordem jurídica brasileira.

Ademais, a partir da oitiva dos áudios das reuniões do CONAD que colocaram em pauta (19.12.217) e que aprovou a Resolução CONAD n. 01/2018 (01.03.18) é possível verificar a utilização de artifícios para aprovação da Resolução, desde o cerceamento de palavra, troca de membros do Conselho, negativa de vistas do processo, e exposição confusa das propostas de mudança na redação do texto.

A aprovação e aplicação da Resolução CONAD n. 01/2018 demonstra a necessidade de maior atenção das instituições, organismos, entidades e pessoas que estudam e trabalham o tema envolvendo a drogadição, exigindo maior fiscalização ao comportamento governamental, pois uma onda retrógrada na política de drogas vem sendo implantada, paulatinamente, em todos os setores que atuam com essa política.

\section{REFERENCIAS}

ALBUQUERQUE, Bernardo Starling. Idade doida da pedra: Configurações históricas e antropológicas do crack na contemporaneidade. In: SAPORI, Luis Flávio; MEDEIROS, Regina (Orgs.). Crack: um desafio social. Belo Horizonte: PUC Minas, 2010.

CARVALHO, Salo de. A Política de Drogas no Brasil: estudo criminológico e dogmático da Lei 11.343/2006. São Paulo: Saraiva, 2010.

Conselho Federal de Psicologia; Mecanismo Nacional de Prevenção e Combate à Tortura; Procuradoria Federal dos Direitos do Cidadão / Ministério Público Federal. Relatório da Inspeção Nacional em Comunidades Terapêuticas. Brasília DF: CFP, 2018.

FIOCRUZ, Centro de Estudos Estratégicos da FIOCRUZ: Pesquisa, política e ação em Saúde Pública. Disponível em: < http://cee.fiocruz.br/?q=Conselho\%20Nacional\%20de\%20Pol\%C3\%ADticas\%20sobre \%20Drogas\%20aprovou\%20proposta\%20do\%20ministro\%200smar\%20Terra\%20que \%20suprime\%20a\%20pol\%C3\%ADtica\%20de\%20Redu\%C3\%A7\%C3\%A3o\%20de\% 20Danos>. Acesso em 20 mar 2019. 
MANSANERA, Adriano Rodrigues; SILVA, Lúcia Cecília da. A influência das ideias higienistas no desenvolvimento da psicologia no Brasil. Psicologia em estudo. v. 5, n. 1. 2000. Disponível em: <http://www.scielo.br/scielo.php?pid=S1413-

$73722000000100008 \&$ script=sci_arttext $>$. Acesso em: 20 out. 2015.

MORAES, Maria Celina Bodin de. A constitucionalização do direito civil e seus efeitos sobre a responsabilidade civil. In: PEREIRA NETO, Cláudio de Souza; SARMENTO, Daniel (Coords.). A constitucionalização do direito. Rio de Janeiro: Lumen Juris, 2007.

PASSETTI, Edson. Abolicionismo penal, medidas de redução de danos e uma nota trágica. Revista Verve, revista semestral autogestionária do Nu-Sol. 7: 75-85. 2005. Disponível em: https://revistas.pucsp.br/verve/article/view/5021/3563.Acesso em 04 mar 2019.

RIBEIRO, Maurídes de M. Drogas e Redução de Danos: os direitos das pessoas que usam drogas. São Paulo: Saraiva, 2013.

SARLET, Ingo Wolfgang; MARINONI, Luiz Guilherme; MITIDIERO, Daniel; Curso de Direito Constitucional. 2 ed. São Paulo: Revista dos Tribunais, 2013.

SBPC - Sociedade Brasileira para o progresso da Ciência, 2018. Após votação polêmica no Conad, SBPC elaborará documento para analisar o debate. Disponível em: < http://portal.sbpcnet.org.br/noticias/apos-votacao-polemica-no-conad-sbpcelaborara-documento-para-analisar-o-debate/>.Acesso em 05 mar 2019.

SICAD. Serviço de Intervenção nos comportamentos aditivos e nas dependências. Disponível em: < http://www.sicad.pt/PT/Cidadao/DesConsumo/Paginas/default.aspx >. Acesso em 01 abr 2019.

WEIGERT, Mariana de Assis Brasil e. O uso de drogas e sistema penal: entre o proibicionismo e a redução de danos. Rio de Janeiro: Lumen Juris, 2010.

\section{Documentos Jurídicos}

BRASIL. Constituição da República Federativa do Brasil. Brasília: Senado Federal, 1988.

Decreto 2.632, de 19 de junho de 1998. Dispõe sobre o Sistema Nacional Antidrogas. Disponível em: . Acesso em: 30 jan. 2019.

Decreto. 4.345, de 26 de agosto de 2002. Institui a Política nacional

Antidrogas. Disponível em: . Acesso em: 02 fev. 2019.

Lei 11.343 de 23 de agosto de 2006. Institui o Sistema Nacional de Políticas

Públicas sobre Drogas - Sisnad... Disponível em: Acesso em: 02 fev 2019. 
CONAD. - Conselho Nacional de Políticas sobre Drogas. Ata n. 2 da reunião

ordinária. 2018. Disponível em: < https://justica.gov.br/sua-protecao/politicas-sobredrogas/conad/atas/2a-reuniao-ordinaria-2018-01-03-ata-assinada-

fisicamente.pdf/view>. Acesso 05 mar 2019.

CONAD. Resolução $n^{\circ} 1$, de 9 de março de 2018. Define as diretrizes para o realinhamento e fortalecimento da PNAD - Política Nacional sobre Drogas... Disponível em: Acesso em 02 fev. 2019.

MINISTÉRIO DA JUSTIÇA. Áudio reunião CONAD de 01 de março de 2018. Disponível em: $<$ https://justica.gov.br/news/politicas-sobre-drogas-dara-guinada-rumoa-abstinencia>. Acesso em: 10 mar 2019.

\section{MINISTÉRIO DA SAÚDE, Política Nacional de Saúde Mental, Álcool e Outras}

Drogas. 2019. Disponível em: $<$ http://portalms.saude.gov.br/politica-nacional-desaude-mental-alcool-e-outras-drogas>. Acesso em: 10 mar 2019.

. Agência Nacional de Vigilância Sanitária - ANVISA

PORTARIA/SVS N ${ }^{\circ}$ 344, DE 12 DE MAIO DE 1998. Aprova o Regulamento Técnico sobre substâncias e medicamentos sujeitos a controle especial. Disponível em:

<http://portal.anvisa.gov.br/documents/10181/2718376/\%2810\%29PRT_SVS_344_199

8_COMP.pdf/5f4fdba8-f3d1-43f1-b41c-0926be4ca06c>. Acesso 01 mar 2019. 